\title{
On certain modern aspects of tourism on the Isle of Man.
}

\author{
Camille Akmut
}

November 21, 2019

\begin{abstract}
Manifesto of the one they call "Phineas Fisher"; and the duties of the historian, and new archives. (Aborted project)
\end{abstract}




\section{Foreword : the conscience of a hacker}

"What's the robbing of a bank next to the founding of a bank?" -

the playwright Bertholt Brecht famously asked. The same also denied morals' hold on poor people : "food before morals!", he asserted boldly.

A similar problem is raised today by someone whose actions and words have reached far :

In the digital age, robbing a bank is a non-violent, less risky act, and the reward is greater than ever. So why are only black hat hackers doing it for their personal benefit, and never hacktivists to finance radical projects? Maybe they don't think they are capable of doing it (...) But, it is not that complicated.

It is because of our collective belief that the financial system is unquestionable that we exercise control over ourselves, and maintain the class system without those above having to do anything. Being able to see how vulnerable and fragile the financial system really is helps us break that collective hallucination.

That is why banks have a strong incentive not to report hacks, and to exaggerate how sophisticated the attackers are. None of the financial hacks I made, or those I've known, have ever been reported. This is going to be the first, and not because the bank wanted to, but because I decided to publish it. ${ }^{12}$

"El hacking, hecho con conciencia". Hacking done with a conscience.

The reader will find this description in one of the arguments of this manifesto. A succinct expression that may also be a good summary of it.

Many topics are evoked, inside this work that is part manual ("DIY"), political economy essay, and autobiography. (And, poem too!)

The author, who cites Goldman and Jeremy Hammond (anarchists appear to be their primary ideological references), writes of

"El capitalismo es un sistema en el que una minoría se ha venido a apropiar de una vasta mayoría de los recursos del mundo..."

- a system in which a minority comes to appropriate a vast majority of the world's ressources, capitalism.

The free software movement ("el movimiento del software libre"), the wider "hacker" community ("la comunidad hacker en general"), the Tor project, cryptographers and privacy/anonymity activitists ("criptógrafos y activistas que defienden la privacidad y el anonimato") and pop culture references (e.g. Fsociety) are mentioned, among others.

\footnotetext{
1 "Hacking a bank and transferring money through the SWIFT network (...) is something totally possible (...) with only public tools and basic knowledge of how to write a script." ...

${ }^{2}$ Note we relied on a translation here (see references). We used knowledge of other languages for the rest.
} 
The fundamental problems of our society have not changed since Engels and Marx' manifesto.

But, the practical means have, both by which we are attacked (e.g. modern surveillance), and by which we can defend ourselves :

What this author calls gaily a "hack back" - a slap returned to the profiteers of this world.

A good heart paired with a sound mind is seldom found;

Just as a good person was hard to find in Szechwan...

\section{REFERENCES}

- Hack Back! Una guía DIY para robar bancos.

- "Hack Back! A DIY guide to rob banks". https://pastebin.com/8rXhtqgr 


\section{Introduction}

These archives - for they are archives in all senses of the word - are part of the many new sources that historians will hopefully soon recognize to be theirs.

They were theirs all along, in fact. But, we must leave them more time yet...

May these anachronistic intellectuals find a way to their own times, somehow. /

Partial inventory of the "Sherwood" archives. Container CN-DC1. 